\title{
Multi-technique characterization and conservation of an ancient Egyptian fabric from King Khufu first solar ship
}

\section{Eman Nabil}

Royal Chariots Museum

Tawfik A. Khattab

National Research Center

samir kamel ( $\nabla$ samirki@yahoo.com )

National Research Center https://orcid.org/0000-0002-7971-4318

\section{Original Research}

Keywords: King Khufu, Solar ship, Linen fender, Analytical methods, Conservation

Posted Date: February 18th, 2021

DOI: https://doi.org/10.21203/rs.3.rs-202536/v1

License: (1) (i) This work is licensed under a Creative Commons Attribution 4.0 International License.

Read Full License 


\section{Abstract}

Textiles are among the most fragile artefacts in the world. They have been difficult to preserve even in the best circumstances. Herein, we studied an artefact fabric of a special nature in terms of usage. Despite the multiple applications of textiles, the piece understudy is one of the unique pieces that the ancient Egyptian used as fenders for King Khufu first solar boat which is the second-largest discovery in Egypt history. The boat was discovered inside a limestone pit. It was disassembled and arranged in several layers. Four pillows of wrapped fabric were found in the first layer, which were used as boat fenders. This use is in itself a great discovery of the role played by textiles in the manufacture of ancient boats. Thus, we conducted tests and analytical studies of those fenders using a scanning electron microscopy (SEM) and an optical microscope to identify the type and nature of fibers, spinning method and aspects of damage. Both energy-dispersive X-ray (EDX) analysis and infrared analysis (FT-IR) were employed to explore the elemental content of the sample and to study the functional groups of the fabric. These analytical processes were useful in carrying out the restoration and preservation work necessary for the artefact under study.

\section{Introduction}

Textile research has been of growing interest within the field of archeology because of its potential to offer relevant information concerning the technical advancements, socio-economic and religious functions of textiles in ancient civilizations $(1,2)$. Textile archaeology searches the dating of the archaeological samples using different techniques. It is a significant branch of culture studies because textiles are a major characteristic of craft manifestation which is associated with cultures of nations ( 3 , 4). Ancient and prehistoric objects have introduced remarkable proof correlated to textile items as presented in paints and sculptures. Linen fabrics are the oldest textile products employed for dating purposes back thousands of years BCE. Ancient Egyptian clothing was mainly made of linen which in turn was made of the well-known strong and long flax fibers (5-7). Textiles suffer from natural aging, such as thermal, chemical and photochemical degradation as well as microbial attack $(8,9)$. Heating cellulose leads to cross-linking amid two hydroxyl substituents on two cellulosic polymer chains forming stiffer fibers (10). Furthermore, cellulosic polymer chains may also be exposed to cleavage process due to free-radical thermo-oxidative process. In the presence of acidic conditions, bonds cleavage is increased (11). Thus, aqueous conservation procedures usually include removal process of acidity with caution because high alkalinity can lead to higher degradation rate during the aging course (12). The rate of thermal decay can also be increased by moisture and other catalysts, such as transition metals which have been suggested as catalysts for the oxidative decay of cellulose (13-16).

Textiles have a glorious past in Egypt since ancient times, and they reflect the pattern of change in every country of civilization. It has multiple uses for various purposes of life and has played a large role in many industries. Especially the manufacture of boats that were developed extensively in the era of Egypt Old Kingdom as a result of developing the needs of the Egyptian religious or secular society. Egyptians became in urgent need of huge large boats that made long trips $(17,18)$. Examples of these boats are 
first solar boat of King Khufu, which is the largest wooden boat found in the whole world. It was confirmed that the craft of making boats is an organized craft. It is based on many materials, including basic materials, such as Arundo, papyrus and wood; and auxiliary materials, such as ropes, mats and linen (19-21). The auxiliary materials in Khufu boat played a large role in the boat construction technique as the ropes were used to connect and assemble the boat parts. The mats were also used to cover and protect the boat during the burial period. Interestingly, the ancient Egyptian used textile pillows as fenders that were fixed on wooden plates or rafters at the four ends of the boat with a rope to absorb shocks when the boat collide with the shore (Figure1).

It is of high significance in cultural heritage research to use nondestructive techniques. Modern analytical nondestructive techniques are playing increasingly important roles in the field of textile archaeology (22, 23). This paper describes the characterization and conservation processes of an Ancient Egyptian fabric employed as fenders in King Khufu first solar boat employing a number of scientific and nondestructive analytical techniques in order to present a deeper conclusion for the deterioration state, and a better realization of how was and/or will be preserved the artefact item. We analyzed an ancient Egyptian fabric from King Khufu first solar ship and this will be helpful in carrying out the conservation work necessary for the current artefact.

\section{Materials And Methods}

\section{Materials}

Ancient Egyptian artefact fabrics were obtained from Giza Solar boat museum. The fabrics were used as fenders in King Khufu first solar ship. Panels made from Cardboard (185/200 GSM) and foam (White Smooth Surface Archival Buffered Acid-Free Foam Board, Pkg of 10 Sheets Antique White 40x'32 6Thick), and equipped with cotton handles were designed to facilitate the handling of the artwork until the completion of the restoration work and complete transportation to the place designated for them either for museum display or storage. Stand with a drawer shape lined from the inside with two layers of polyethylene were employed for storage. This drawer method is an excellent method used to save smallsized artifacts. Japanese papers were used to cover the carrier drawer for artifacts suffered from fragility. Cedar oil was obtained from the local Egyptian market; to be applied as a natural sterilizing substance against infectious fungi. Beva 371 was purchased from the local Egyptian market and was applied to strengthen the fabric. Beva 371 (Berger ethylene vinyl acetate) is a product based on ethylenevinylacetate, paraffın, ketone resin, $40 \%$ solids content in aliphatic and aromatic solvents. Gustav Berger's 0. F. 371, used in combination with the special Thinner 372, forms a reversible adhesive with good elasticity and chemical stability. Appearance: opalescent gel, solids content $\sim 40 \%$ melting point is $68^{\circ} \mathrm{C}$ and flash point $<21^{\circ} \mathrm{C}$.

\section{Methods and apparatus}

In this study, different analytical approaches such as scanning electron microscope (SEM) images, energy-dispersive X-ray (EDX) spectra, optical microscopy and Fourier transformed infrared (FT-IR) 
spectra were employed to elucidate the constituents and original nature of an ancient Egyptian fabric from Khufu first solar ship at Giza solar boat museum as well as to better accomplish the conservation status of this artefact fabric.

\section{Field-emission scanning electron microscopy}

The morphology of the current artefact fabric was examined by field-emission scanning electron microscopy (FE-SEM) using a Quanta-FEG250 (Czech Republic) with an accelerating voltage of $20 \mathrm{kV}$.

\section{Energy-dispersive X-ray spectroscopy}

The elemental content and distribution were investigated by surface energy-dispersive X-ray (EDX) spectroscopy unit (TEAM-EDX Model) connected to the scanning electron microscope. The EDX spectra were recorded at a work distance of $21 \mathrm{~mm}$ and an acceleration voltage of $20 \mathrm{kV}$.

\section{Optical microscope}

The structure of the artefact fabric used in the pillow under study was studied by optical microscopy on an Axiocam MRC5 camera (Imager M1, Zeiss).

\section{Fourier transform infrared spectroscopy}

FT-IR spectra (transmission mode) were recorded by direct contact of the sample with the detector of FTIR spectrophotometer (Nexus 670, Nicolet, USA). The measurements were reported between $4000-400 \mathrm{~cm}^{-}$ ${ }^{1}$ using a $4.0 \mathrm{~cm}^{-1}$ spectral resolution.

\section{Visual evaluation}

The naked-eye evaluation was applied to study the state of the external surface of an artefact.

\section{Conservation process}

Depending on the assessment results of the various analytical techniques, the conservation process was performed to get rid of the deposits from the artefact fabric surface and to preserve it against future aging.

\section{Microbial deterioration}

The microbial deterioration was monitored at the conservation center of Grand Egyptian Museum according to previously reported procedure (24). The sampling process included several tools including cotton swab, adhesive tape and grinding process. The isolation media of fungi was carried out using potato dextrose agar medium (PDA; Nissui) and Lignin cellulose medium (LCM; Nissui). In addition, modified Czapeck's medium was prepared by adding lignin cellulose as a carbon source instead of sucrose. This medium composed of lignin cellulose $\left(10.00 \mathrm{~g} \mathrm{~L}^{-1}\right)$, potassium phosphate dibasic trihydrate 
$\left(\mathrm{KH}_{2} \mathrm{PO}_{4} .3 \mathrm{H}_{2} \mathrm{O} ; 1.00 \mathrm{~g} \mathrm{~L}^{-1}\right)$, sodium nitrate $\left(\mathrm{NaNO}_{3} ; 10.00 \mathrm{~g} \mathrm{~L}^{-1}\right)$, potassium chloride $\left(\mathrm{KCl} ; 0.50 \mathrm{~g} \mathrm{~L}^{-1}\right)$, magnesium sulfate heptahydrate $\left(\mathrm{MgSO}_{4} \cdot 7 \mathrm{H}_{2} \mathrm{O} ; 0.50 \mathrm{~g} \mathrm{~L}^{-1}\right)$, ferrous sulfate heptahydrate $\left(\mathrm{FeSO}_{4} \cdot 7 \mathrm{H}_{2} \mathrm{O}\right.$; $\left.0.01 \mathrm{~g} \mathrm{~L}^{-1}\right)$ and Agar $\left(20.00 \mathrm{~g} \mathrm{~L}^{-1}\right)$. All of the above media were amended with antibacterial agent (chloramphenicol (. The isolation media of bacteria included nutrient agar medium (Nissui).

\section{Results And Discussion}

\section{Archaeological description and visual examination}

In 1954, the largest boat in history (Khufu first solar ship), which dates back to the ancient Egyptian state, was discovered inside an underground limestone hole, disjointed and arranged in layers. The first layer comprised four textile pillows among a group of boat paddles. The piece under study is one of those pillows reported under the record number 320 in Khufu Museum. In the place of discovery, the first layer was found loaded on a side wooden plate between the first and second paddles. According to the museum records, the dimensions of the piece at the moment of discovery were $66 \mathrm{~cm}$ length and $36 \mathrm{~cm}$ width. According to the archaeological description, the pillow was made of thick layers of fabric previously reinforced at the surface with Markon Resin 9 Low Viscosity (Scott and Bader Co.Ltd.) dissolved in acetone as described in Figure 2.

The visual examination is the first step to study the state of the external surface of an artefact. It was found through the visual examination of the pillow state, and compared to the documentary pictures at the moment of discovery, how weak, fragmented and shattered the state of the pillow reached due to poor storage (Figure 3).

\section{Morphological properties}

\section{Optical microscopy}

It was proved by the optical microscopic examination that linen was applied in the manufacture of boat fenders. Through the microscopic examination, it became clear that the fabric was constructed from the fibers of the linen plant due to the presence of distinctive bronchioles as shown in Figure 4. Flax is one of the oldest plants grown in prehistoric Egypt. It was mentioned that the ancient Egyptian used a type of linen called Linum humile Mill from which all kinds of linen fabric were derived (25). Linen fabric has been used a lot in the manufacture of boats, such as sails, and it was dyed with a variety of colors. It was also used in covering the cabins $(25,26)$.

\section{Scanning electron microscopy}

Scanning electron microscope (SEM) images were applied to inspect the fabric characteristic morphological diagnostic features to identify the various manifestations of damage and judging the surface structure of the sample under study. Different studies of fibers at both microscopic and visual levels have a significant impact on exploring the behavior and deterioration of fabric as well as the 
properties of fabric, which can help a lot in how to maintain them. There are three major factors that identify the properties of any textile, including the shape of the fibers, the source of the fibers, and how the final product is built. According to the external qualitative examination of the sample, it became evident that there was a severe cracking on the fabric surface as well as calcifications, dust and dirt. Previous reinforcing materials covering the fabric surface were also monitored as shown in Figure5. SEM images demonstrated that of the fabric surface exhibited high roughness associated with damages, cracks, small holes and slits. Microchannels of a diameter range between 5-50 $\mu \mathrm{m}$ were monitored. SEM images of the fabric exposed to conservation treatment indicated that the fabric surface was consistently coated with a film of Beva 371. The fabric thickness was in the range between 1.0 and $1.5 \mathrm{~mm}$. The textile structure displayed a simple plain $1 / 1$ weave with one over and one under interlocking of circularly twisted yarns.

\section{Elemental composition}

\section{Energy dispersive X-ray spectroscopy}

The elemental examination carried out on this type of artefact fabric led to a full understanding of its nature and the extent of deterioration, which helped in setting a plan to preserve this type of heritage. Energy dispersive X-ray analysis (EDX) was applied to identify the precise internal structure of the linen. It has also verified to be very efficient in detecting and determining the extent of damage in linen. It was possible to study the changes that occurred in the original composition of the archaeological textile resulting from saturation with the reinforcing materials. Scanning electron micrographs were subjected to EDX mapping (Figure6), while their corresponding EDX spectra representing the quantitative elemental composition of the heritage sample are shown in (Table 1). The total content results were taken before and after performing the conservation treatment process. A close-up view of both samples displayed high contents of both carbon (C) and oxygen ( $\mathrm{O}$ ) existing as major elements of linen structure. The other elements, including silicone $(\mathrm{Si})$, aluminum (Al), magnesium $(\mathrm{Mg})$, nitrogen $(\mathrm{N})$ and calcium $(\mathrm{Ca})$ were found through the samples which might be the constituent of regular formation of the wash layer. The indication of iron $(\mathrm{Fe})$, sodium $(\mathrm{Na})$ and potassium $(\mathrm{K})$ were obtained as minor elements. The existence of oxygen suggests that the majority of elements exist as oxides. Alumina (from old conservation materials) and cupper-based conservation materials (from the current conservation materials) have been known as stiffening agents. The elements including calcium, silicon and iron suggest that the fabric might be painted with natural pigments such calcium carbonate (calcite) and metal oxides, which is reliable with the previously reported results in the field of Archaeology (27).

Table 1. EDX results of the fabric before and after conservation. 


\begin{tabular}{|lllll|}
\hline \multirow{2}{*}{ Element } & \multicolumn{2}{l}{ Before conservation } & \multicolumn{2}{l|}{ After conservation } \\
\cline { 2 - 5 } & Wt\% & At\% & Wt $\%$ & At\% \\
\hline $\mathrm{C}$ & 45.5 & 57.2 & 29.68 & 55.2 \\
\hline $\mathrm{N}$ & 1.37 & 1.48 & - & - \\
$\mathrm{O}$ & 33.91 & 32 & 9.95 & 13.89 \\
$\mathrm{Na}$ & 2.36 & 1.55 & 14.75 & 14.33 \\
$\mathrm{Mg}$ & 0.68 & 0.42 & - & - \\
$\mathrm{Al}$ & 2.7 & 1.51 & - & - \\
\hline $\mathrm{Si}$ & 6.93 & 3.73 & - & - \\
\hline $\mathrm{K}$ & 0.71 & 0.27 & - & - \\
\hline $\mathrm{Ca}$ & 2.39 & 0.9 & - & - \\
\hline $\mathrm{Fe}$ & 3.44 & 0.93 & 11.2 & 4.48 \\
\hline $\mathrm{Cu}$ & - & - & 34.43 & 12.1 \\
\hline
\end{tabular}

\section{Fourier-transform infrared spectroscopy}

FT-IR spectra were employed to verify the functional groups of the ancient fabric. The distinctive peaks of linen within FT-IR chart are displayed in Figure7. The detected bands were consistent among blank/pristine linen sample and the artefact fabric before and after conservation treatment. The characteristic broad peak for the vibration stretch of hydroxyl substituents $(-\mathrm{OH})$ was monitored at 3428 $\mathrm{cm}^{-1}$. The vibration stretch of the ether groups (-C口OO-) appeared as an acute intense peak at $1030 \mathrm{~cm}^{-1}$. Aliphatic $\mathrm{CH}$ groups appeared at $2924 \mathrm{~cm}^{-1}$.

All of the fibers in the CPFC display bands typical of cellulose. These include: a broad band between 3600 and $3200 \mathrm{~cm}^{-1}$ attributable to hydrogen bonded $\mathrm{O} \mathrm{H}$ stretching, a band around $2900 \mathrm{~cm}^{-1}$ which is related to $\mathrm{C} \mathrm{H}$ and $\mathrm{CH} 2$ stretching vibrations, and numerous bands in the region from $1500-1200 \mathrm{~cm}^{-1}$ that are related to vibration modes of $\mathrm{OH}$ and $\mathrm{C} \mathrm{H}$ groups. While pure cellulose might not display any bands in the region from 2000-1500 cm-1 except one at around $1635 \mathrm{~cm}^{-1}$, the presence of bands around $1700 \mathrm{~cm}^{-1}$ is indicative of $\mathrm{C} \mathrm{O}$ moieties stemming from cellulose oxidation or esterification. There are many bands in the region of $1300-900 \mathrm{~cm}^{-1}$. This part of the spectra is called the fingerprint region, and small differences in this area can be linked to structural changes in the cellulose.

\section{Treatment and conservation}

The real purpose of the treatment process is to preserve the artwork for the next generations to study its value. The current artefact piece was subjected to poor storage conditions leading to its secession into 
multiple pieces in addition to the secession of fabric layers, weakness and extreme fragility that made it vulnerable to loss. The research is concerned with maintaining and stabilizing the piece under study, and stopping the continuous bleeding of the fabric fibers. The stages of treatment were as follows:

\section{Methods of handling and transportation of the textile artefacts}

The linen pillow under study was found as one piece with dimensions of $66 \mathrm{~cm}$ length and $36 \mathrm{~cm}$ width. The bad storage conditions led to the fragmentation of the linen pillow into 28 pieces. Each piece was recorded separately and its dimensions were determined without subjecting the piece to pressure or touch. The lengths of the fragmented parts ranged between 4.5 to $17 \mathrm{~cm}$, while the widths were in the range between 2.3 and $7.0 \mathrm{~cm}$. Precision and extreme caution when dealing with decomposed linen textiles is crucial to maintain the artwork because those types of artefacts have a deceptive appearance of force upon discovery. By examination and analysis, the artefact condition was confirmed and its severe weakness and fragility were difficult to deal with by hand. Therefore, it was necessary to use specialized methods to transmit and address this artefact. Panels made from safe materials were designed to facilitate the handling of the artwork until the completion of the restoration work and transfer them to the place designated for them either for museum display or storage. The carrier panels were made from safe acid-free materials, such as cardboard and foam, equipped with cotton handles. The type of panel was chosen according to the size, thickness and weight of the artefact piece. It was preferred to use a thin and fine polyethylene, known as Volara Foam, for weak and fragile linen bits. Finger-holds were cut on each side of the panel for easy transportation of the artefact. Japanese papers were also used to cover the carrier panels for artefacts suffered of fragility (Figure 8).

\section{Mechanical surface cleaning}

This is the most important initial step to remove dust and dirt stuck to the surface of the artefact. The mechanical cleaning stages were performed with great care due to the fragility and weakness of the artefact. The vacuuming process was performed with a low power cleaner equipped with a rubber-based nozzle. The hand blower was applied at an enough distance away from the artefact to prevent volatilization of the detached textile parts (Figure 9).

\section{Sterilization process}

Textiles are made of organic materials which can be easily exposed to fungal infection. Thus, the sterilization work was done using cedar oil as a natural substance used successfully to sterilize against infectious fungi by placing cedar oil inside a tightly closed room containing the artefact for a period of two weeks. The closed room was prepared from polyethylene, inside which the sterilization stage was completed.

\section{Strengthen procedure}

Due to the extreme weakness of the fabric; it was necessary to perform rapid strengthening works to preserve the artefact and to prevent the continuous deterioration. The strengthening process was carried 
out using Beva 371, which is one of the materials that have been used successfully in the process of textile strengthening (28). Beva 371 a heat activated adhesive that dissolves in non-polar solvents and can be applied at ambient conditions as it does not require a heating procedure. It does not cause any softening or shrinkage to the applied material making it safe to apply to the most sensitive materials. The application also gives a smooth surface after application introducing a natural feeling to the treated fabric as it is a retrieval material that can be easily removed by solvents without fabric deformation. The strengthening process was done by spraying and injecting technology in some parts depending on the fabric condition.

\section{Packaging and storage}

The artefact condition under study is one of the cases that need serious attention after the strengthening and treatment processes. The procedures for future preservation of the artefact were carried out in the restoration laboratories at the conservation center of Giza Solar boat museum. A scientific packaging method was adopted using the lined drawers. This is done by making a stand that takes a drawer shape, lined from the inside with two layers of polyethylene. The first polyethylene layer was fixed to the bottom of the drawer and the second layer was formed by making a cavity that takes the shape of each piece to be placed in it. The cavitation method is one of the excellent methods used with small-sized artefacts, which are usually one artefact and are transferred periodically. The cavity should not too tight to handle the artefact easily through it. It is preferred for the highly weak and brittle pieces to use thin and smooth

polyethylene with fingerprint engraving on each side for easy portability. Upon designing and constructing the panels and drawers, several aspects must be taken into consideration:

- Lining the panels and drawers with polyethylene material and cotton gauze or acid-free textiles, provided that it is well fixed with a double-sided adhesive tape or glue gun. Japanese papers can also be used in the lining process.

- Using acid-free cardboard.

- Using a tape or rope handle made of nylon or cotton.

\section{Microbial deterioration}

The results of studying the microbial deterioration revealed that there is strong fungal infection in all examined samples. Four fungal genera were isolated and identified from the objects on different types of media, including potato dextrose agar medium (PDA) and Lignin cellulose medium (LCM). The ability of fungi to grow on LCM medium revealed their lingocellulosic activity and hence their ability to grow on fabric (Figs. 11 and 12). Bacterial infection was also found as represented by gram negative bacilli displayed in Table 2. Thus, mechanical cleaning is an important step before microbial treatment as it leads to decreased microbial load and therefore decrease the dose required for treatment. Also, chemical treatment is needed to overcome microbial problem.

Table 2. Colony counts of microorganisms in different media. 


\begin{tabular}{|lll|}
\hline Medium & Microorganism & colony count \\
\hline PDA & Aspergillus flavus & 7 \\
& Aspergillus nidulans & 1 \\
& Aspergillus niger & 3 \\
& Paecilomyces variotii & 6 \\
& Penicillium sp. & 26 \\
\hline LCM & Aspergillus flavus & 10 \\
& Aspergillus niger & 5 \\
& Paecilomyces variotii & 8 \\
& Penicillium sp. & 27 \\
& Gram-negative bacilli D & Uncountable \\
& Gram-negative cocci & 1 \\
Nutrient agar & Gram-negative bacilli A & 2 \\
\hline Air sample examination & Aspergillus flavus & 12 \\
& Penicillium sp. & 9 \\
& Ulocladium sp. & 1 \\
\hline
\end{tabular}

\section{Conclusions}

In the present study, archaeological textile sample from King Khufu first solar ship dating back to ancient Egypt state was analyzed and subjected to deep restoration process. The non-destructive identification techniques indicated that ancient Egyptian used linen as boat fenders. The analysis with different techniques including optical microscopy, elemental mapping, energy dispersive X-ray analysis, scanning electron microscope and infrared analysis allowed the identification of the original materials, and the substances added during the previous restoration process. This helped in removing previous restoration substances that disturbed the authenticity of the fabric and to select the most proper cleaning and strengthening measures. The current applied materials and methods were extremely efficient for strengthening and stability of the fabric without causing harmful effects to the original materials. The mechanical cleaning process provided a safe technique to be employed in the fabric conservation. The fabric was successfully conserved and ready for displaying or storing in Giza Solar boat museum.

\section{Declarations}

\section{Acknowledgement}


The authors are thankful for the financial support from National Research Centre (Grant \# 12010206), Egypt.

The authors declare that they have no known competing financial interests or personal relationships that could have appeared to influence the work reported in this paper.

\section{References}

1. Sinding M-HS, Vieira FG, Smith MH. Unmatched DNA preservation prove arctic hare and sheep wool in Norse Greenlandic textile from "The Farm Beneath the Sand". Journal of Archaeological Science: Reports. 2017;14:603-8.

2. Pozzi F, Zaleski S, Casadio F, Leona M, Lombardi JR, Van Duyne RP. Surface-enhanced raman spectroscopy: using nanoparticles to detect trace amounts of colorants in works of art. Nanoscience and Cultural Heritage: Springer; 2016. p. 161-204.

3. Li Y, Wei S, He Q, Fu M. Multi-analytical techniques used for the identification of the dyeing techniques of several textile of ancient China. Microchemical Journal. 2020;156:104790.

4. Alonso A, Martellotta F. Room acoustic modelling of textile materials hung freely in space: from the reverberation chamber to ancient churches. Journal of Building Performance Simulation. 2016;9(5):469-86.

5. De Caro L, Giannini C, Lassandro R, Scattarella F, Sibillano T, Matricciani E, et al. X-ray dating of ancient linen fabrics. Heritage. 2019;2(4):2763-83.

6. De Caro L, Matricciani E, Fanti G. Yellowing of Ancient Linen and Its Effects on the Colours of the Holy Face of Manoppello. Heritage. 2020;3(1):1-18.

7. Ferrari M, Mazzoli R, Morales S, Fedi M, Liccioli L, Piccirillo A, et al. Enzymatic laundry for old clothes: immobilized alpha-amylase from Bacillus sp. for the biocleaning of an ancient Coptic tunic. Applied Microbiology and Biotechnology. 2017;101(18):7041-52.

8. Micheal M, Tera F, Othman E. Degradation measurements of linen fabrics. Polymer-Plastics Technology and Engineering. 2005;43(5):1377-86.

9. Kourkoumelis N, El-Gaoudy H, Varella E, Kovala-Demertzi D. Physicochemical characterization of thermally aged Egyptian linen dyed with organic natural dyestuffs. Applied Physics A. 2013;112(2):469-78.

10. Henniges U, Bjerregaard L, Ludwig B, Potthast A. Controversial influence of aqueous treatments on historic textiles. Polymer degradation and stability. 2011;96(4):588-94.

11. Conte AM, Pulci O, Knapik A, Bagniuk J, Del Sole R, Lojewska J, et al. Role of cellulose oxidation in the yellowing of ancient paper. Physical Review Letters. 2012;108(15):158301.

12. Corsaro C, Mallamace D, Łojewska J, Mallamace F, Pietronero L, Missori M. Molecular degradation of ancient documents revealed by 1 H HR-MAS NMR spectroscopy. Scientific reports. 2013;3:2896. 
13. Jeong M-J, Kang K-Y, Bacher M, Kim H-J, Jo B-M, Potthast A. Deterioration of ancient cellulose paper, Hanji: evaluation of paper permanence. Cellulose. 2014;21(6):4621-32.

14. Horn SJ, Vaaje-Kolstad G, Westereng B, Eijsink V. Novel enzymes for the degradation of cellulose. Biotechnology for biofuels. 2012;5(1):45.

15. Puls J, Wilson SA, Hölter D. Degradation of cellulose acetate-based materials: a review. Journal of Polymers and the Environment. 2011;19(1):152-65.

16. Tehrani-Bagha A, Mahmoodi N, Menger F. Degradation of a persistent organic dye from colored textile wastewater by ozonation. Desalination. 2010;260(1-3):34-8.

17. Karapanagiotis I, Verhecken-Lammens C, Kamaterou P. Identification of dyes in Egyptian textiles of the first millennium ad from the collection Fill-Trevisiol. Archaeological and Anthropological Sciences. 2019;11(6):2699-710.

18. Fanti G, Baraldi P, Basso R, Tinti A. Non-destructive dating of ancient flax textiles by means of vibrational spectroscopy. Vibrational Spectroscopy. 2013;67:61-70.

19. Mark S. A Different Configuration for the Quarter-Rudders on the Khufu I Vessel (c. 2566 BC), and Egyptian Methods of Mounting Quarter-Rudders and Oars in the 4th and 5th Dynasties. International Journal of Nautical Archaeology. 2012;41(1):84-93.

20. Wegner J. A Royal Boat Burial and Watercraft Tableau of Egypt's 12th Dynasty (c. 1850 BCE) at South Abydos. International Journal of Nautical Archaeology. 2017;46(1):5-30.

21. Mark S. The Abydos BG 10 Boat and Implications for Standardisation, Innovation, and Timber Conservation in Early Dynastic Boat-building. The Journal of Egyptian Archaeology. 2012;98(1):10726.

22. Padilla R, Van Espen P, Torres PG. The suitability of XRF analysis for compositional classification of archaeological ceramic fabric: A comparison with a previous NAA study. Analytica Chimica Acta. 2006;558(1-2):283-9.

23. Khattab TA, Rehan M, Hamouda T. Smart textile framework: Photochromic and fluorescent cellulosic fabric printed by strontium aluminate pigment. Carbohydrate polymers. 2018;195:143-52.

24. Upadhyay N, Singh VK, Dwivedy AK, Das S, Chaudhari AK, Dubey NK. Cistus ladanifer L. essential oil as a plant based preservative against molds infesting oil seeds, aflatoxin B1 secretion, oxidative deterioration and methylglyoxal biosynthesis. LWT. 2018;92:395-403.

25. Smýkal P, Bačová-Kerteszová N, Kalendar R, Corander J, Schulman AH, Pavelek M. Genetic diversity of cultivated flax (Linum usitatissimum L.) germplasm assessed by retrotransposon-based markers. Theoretical and Applied Genetics. 2011;122(7):1385-97.

26. Elgahawi H, Gobara M, Baraka A, Elthalabawy W. Eco-friendly corrosion inhibition of AA2024 in $3.5 \%$ $\mathrm{NaCl}$ using the extract of Linum usitatissimum seeds. Journal of Bio-and Tribo-Corrosion. 2017;3(4):55.

27. Scott DA, Warmlander S, Mazurek J, Quirke S. Examination of some pigments, grounds and media from Egyptian cartonnage fragments in the Petrie Museum, University College London. Journal of Archaeological Science. 2009;36(3):923-32. 
28. Kronthal L, Levinson J, Dignard C, Chao E, Down J. Beva 371 and its use as an adhesive for skin and leather repairs: background and a review of treatments. Journal of the American Institute for Conservation. 2003;42(2):341-62.

\section{Figures}

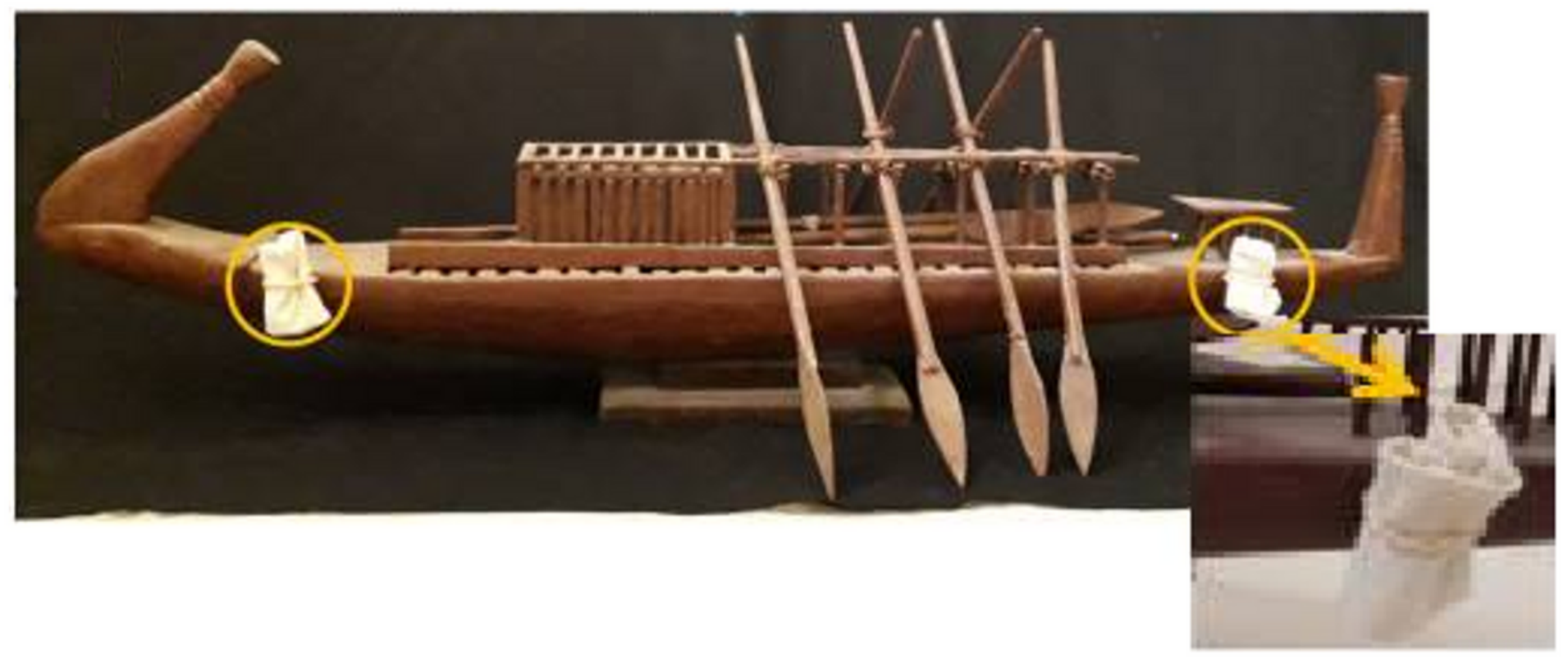

\section{Figure 1}

Wooden model of Khufu's boat demonstrating positions of fenders.
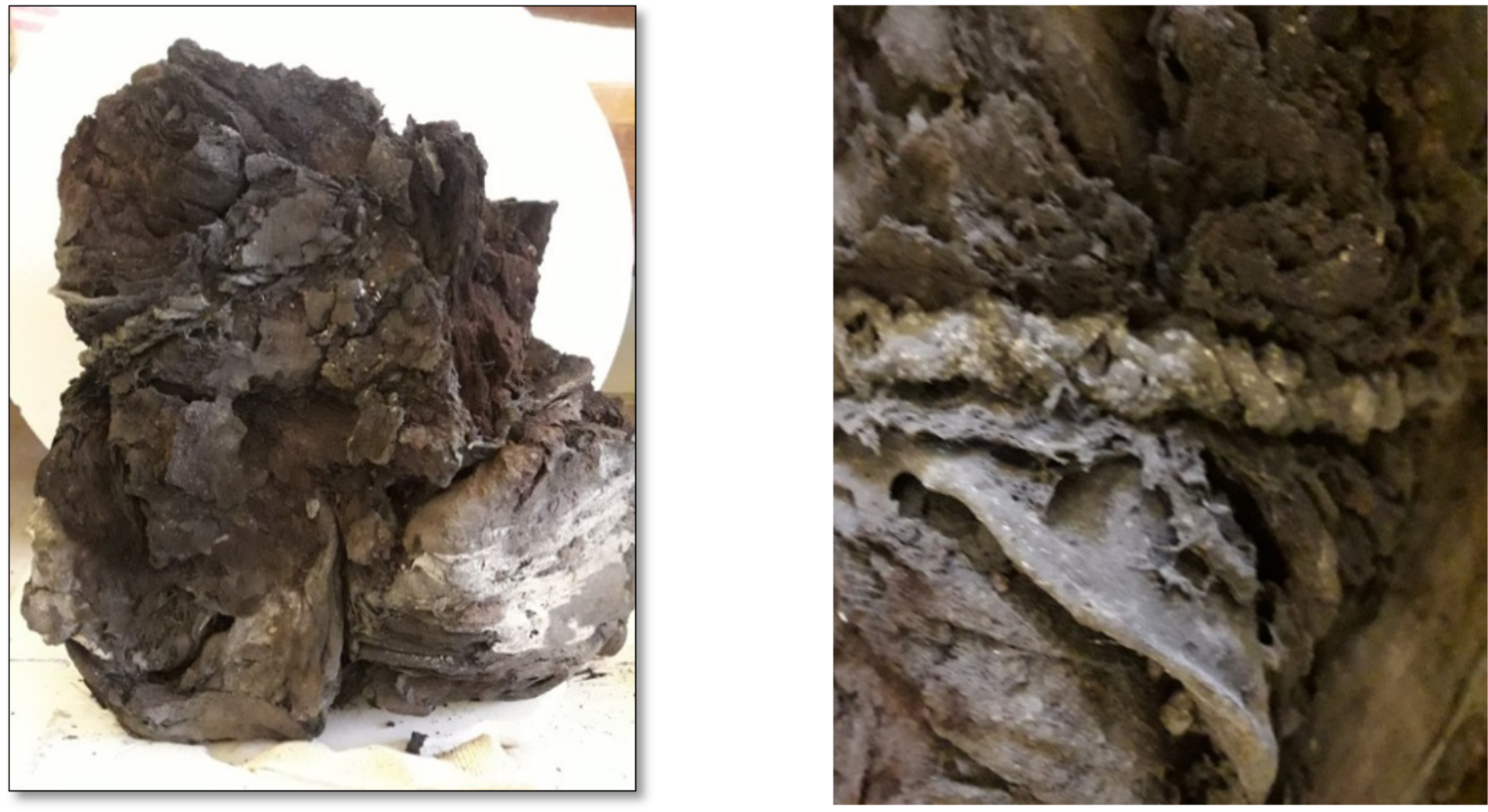
Figure 2

The pillow at the moment of discovery and the shape of the fabric rolls and the rope in the middle area used to fix the piece to the wooden beam.
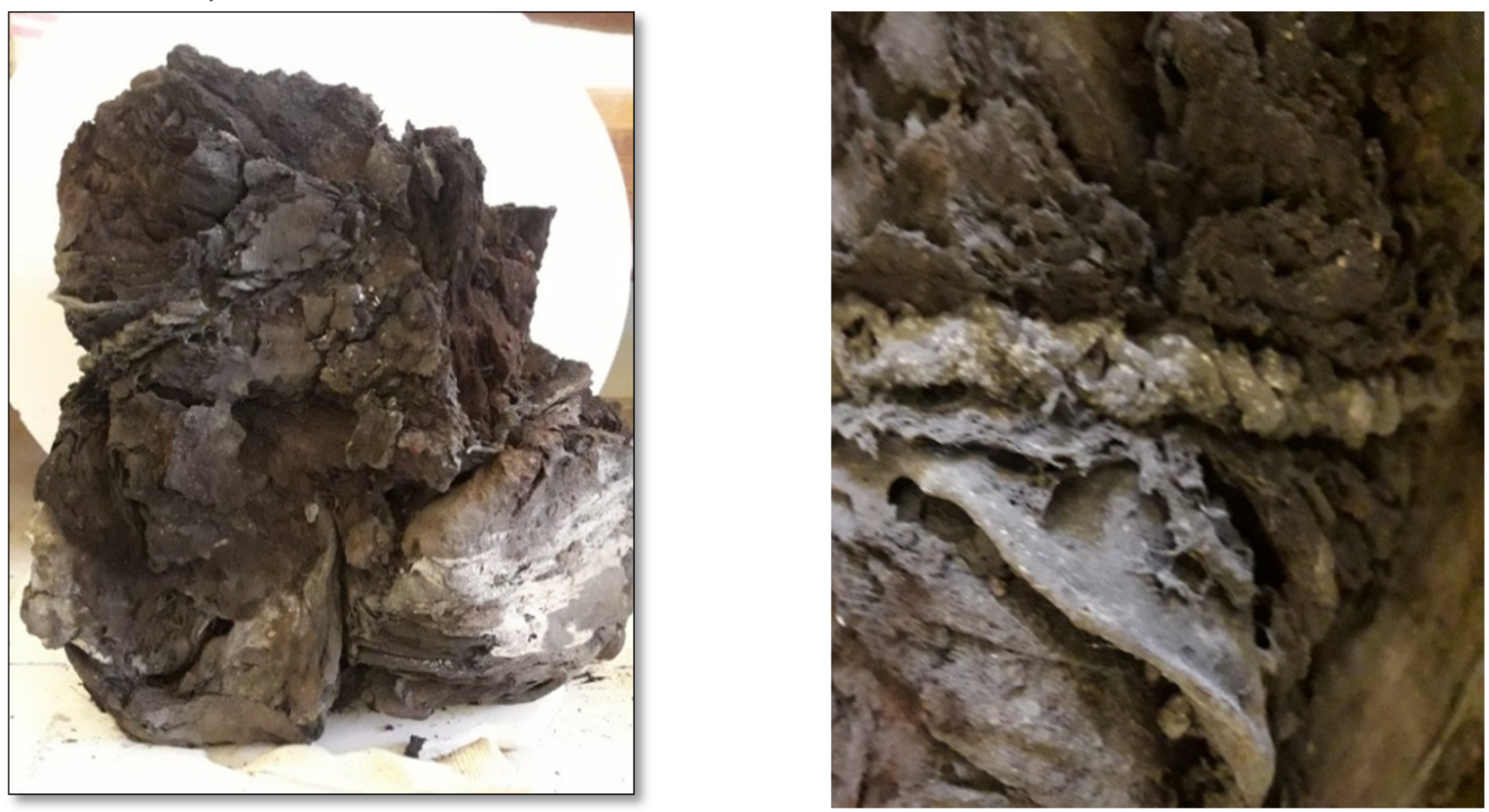

\section{Figure 3}

The pillow at the moment of discovery and the shape of the fabric rolls and the rope in the middle area used to fix the piece to the wooden beam. 


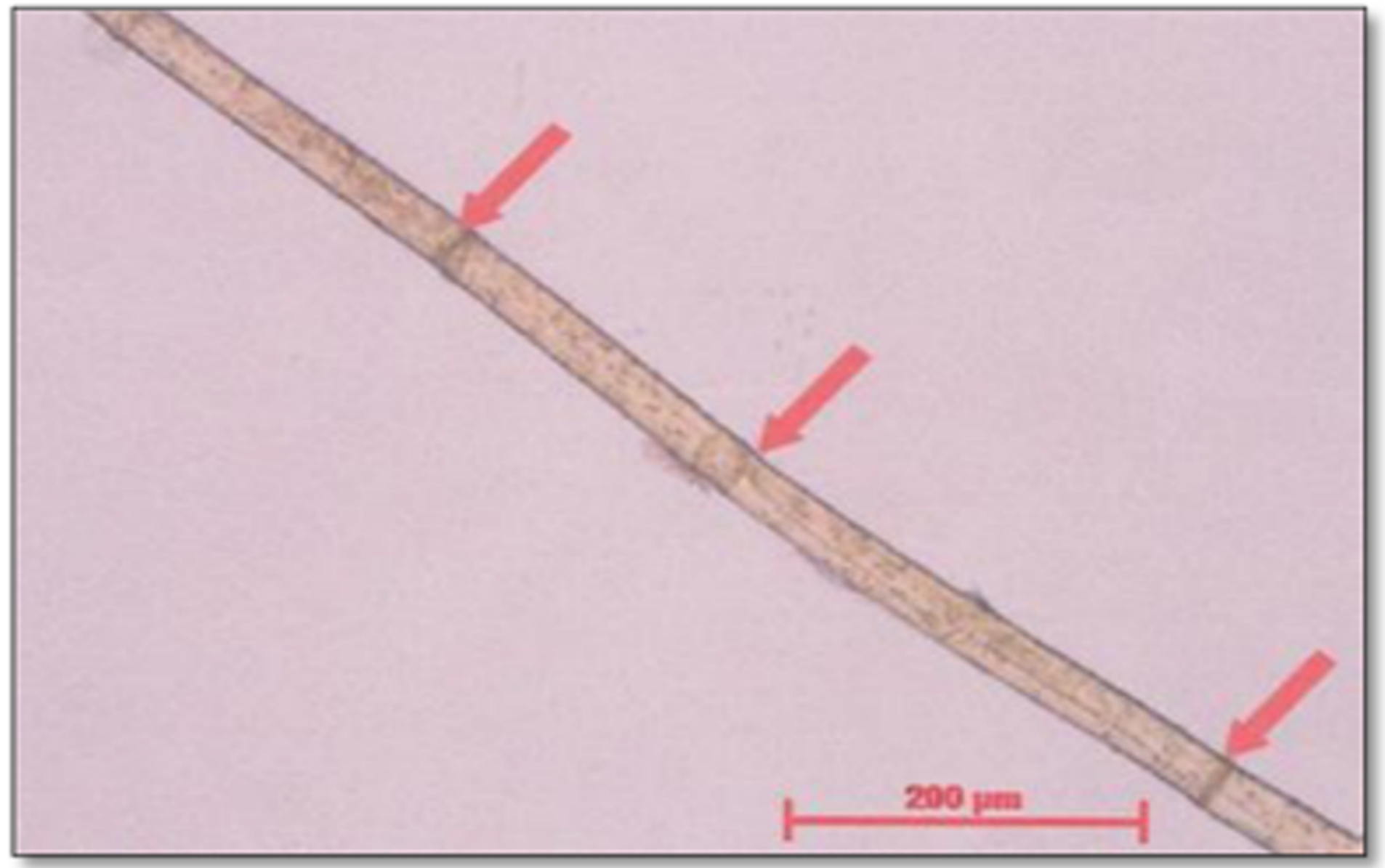

Figure 4

Optical microscope image displaying distinctive nodes on fibers. 

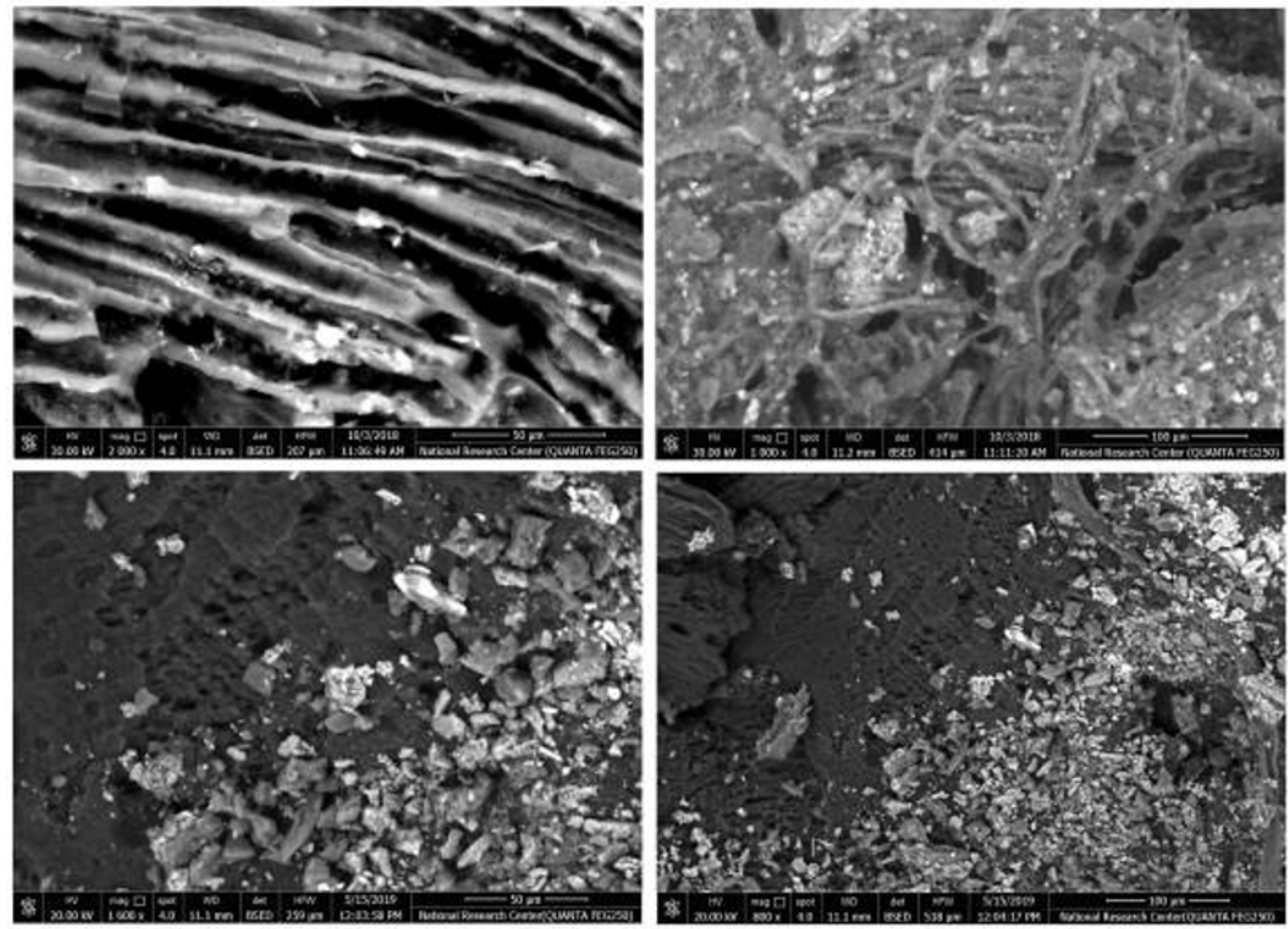

Figure 5

SEM images of the ancient Egyptian fabric from King Khufu's first boat before (top) and after (bottom) conservation. 

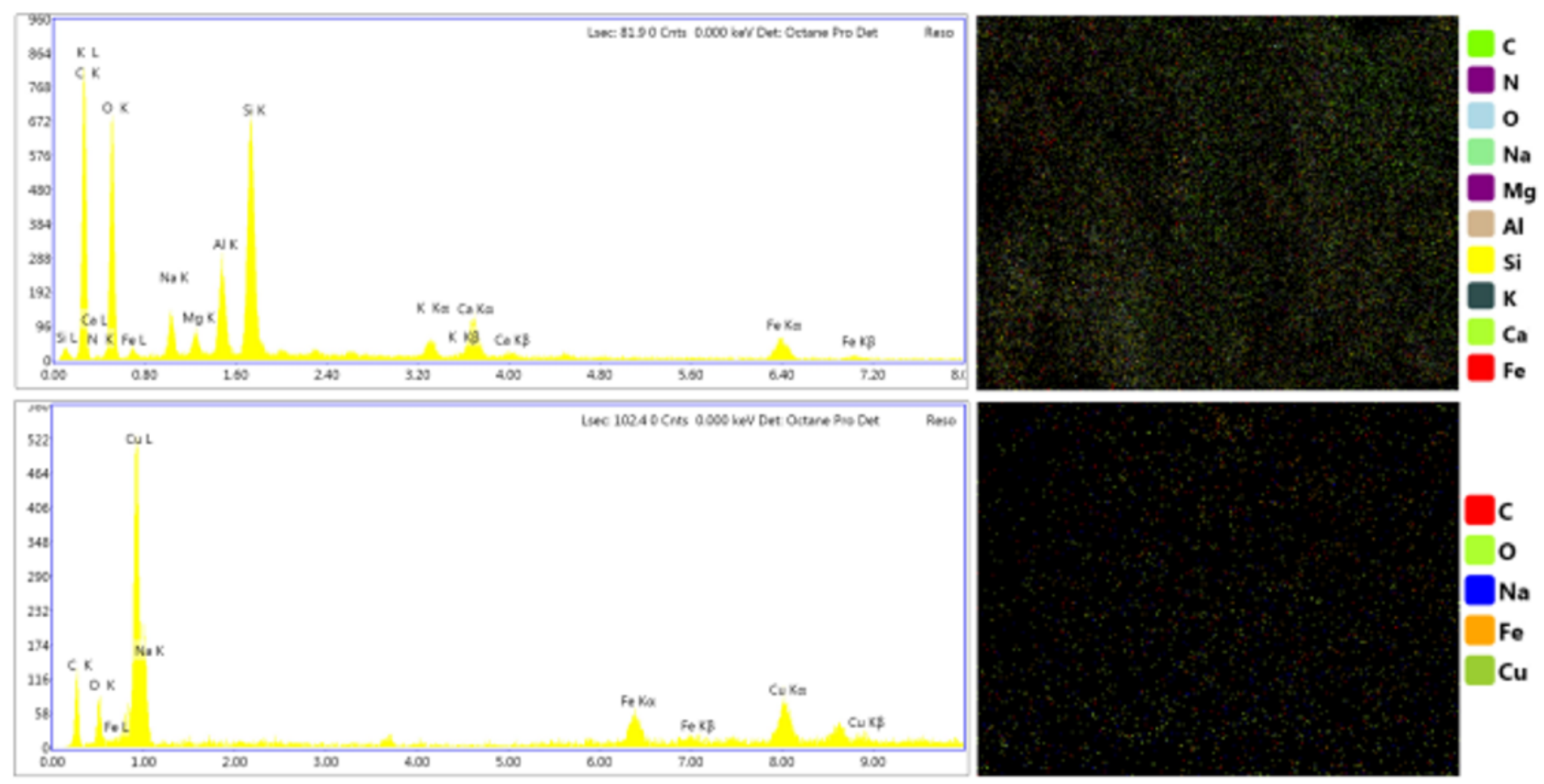

Figure 6

EDX diagram and elemental mapping of the fabric before (top) and after (bottom) conservation. 


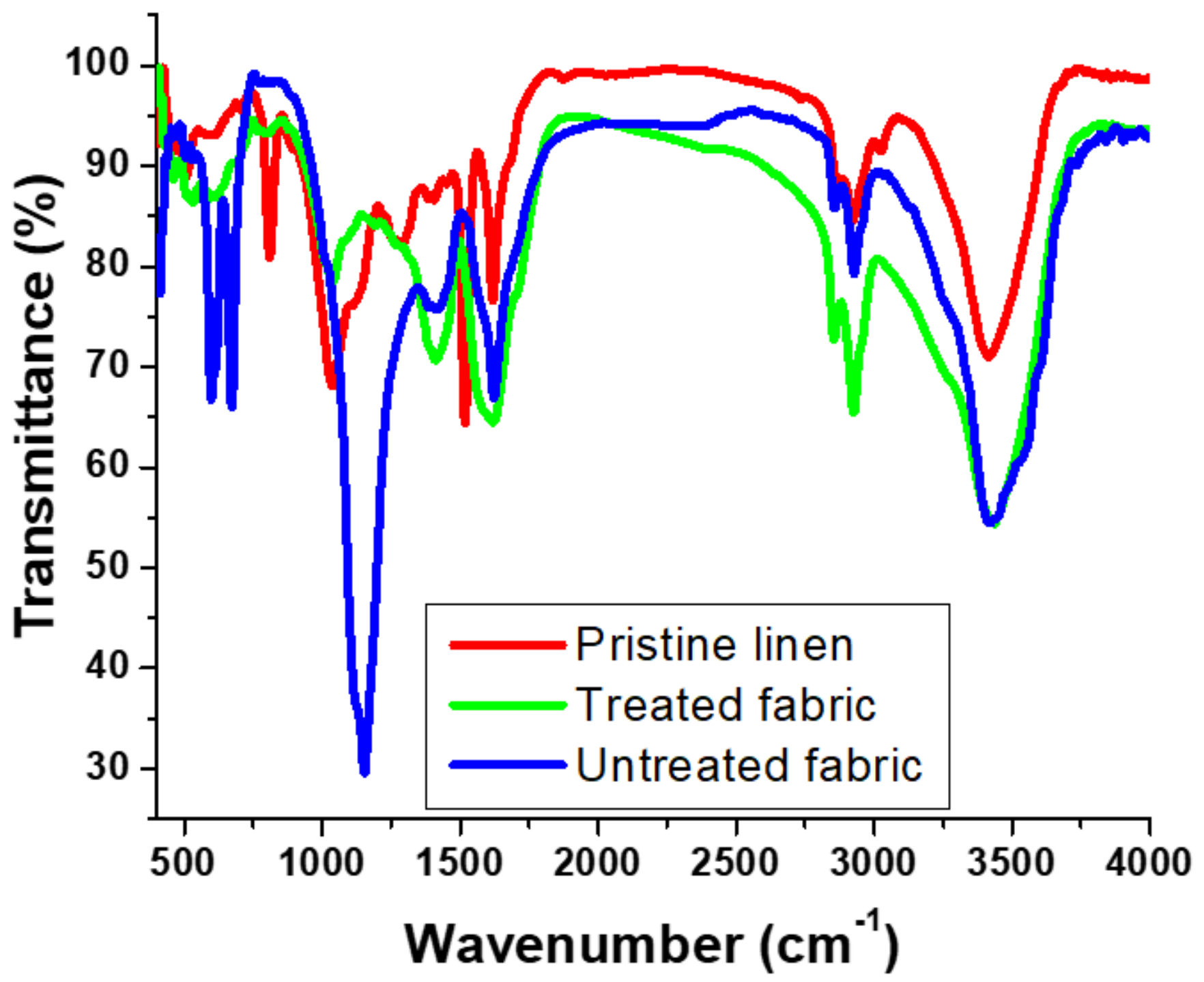

Figure 7

FT-IR spectra of blank linen, treated and untreated artifact fabric. 

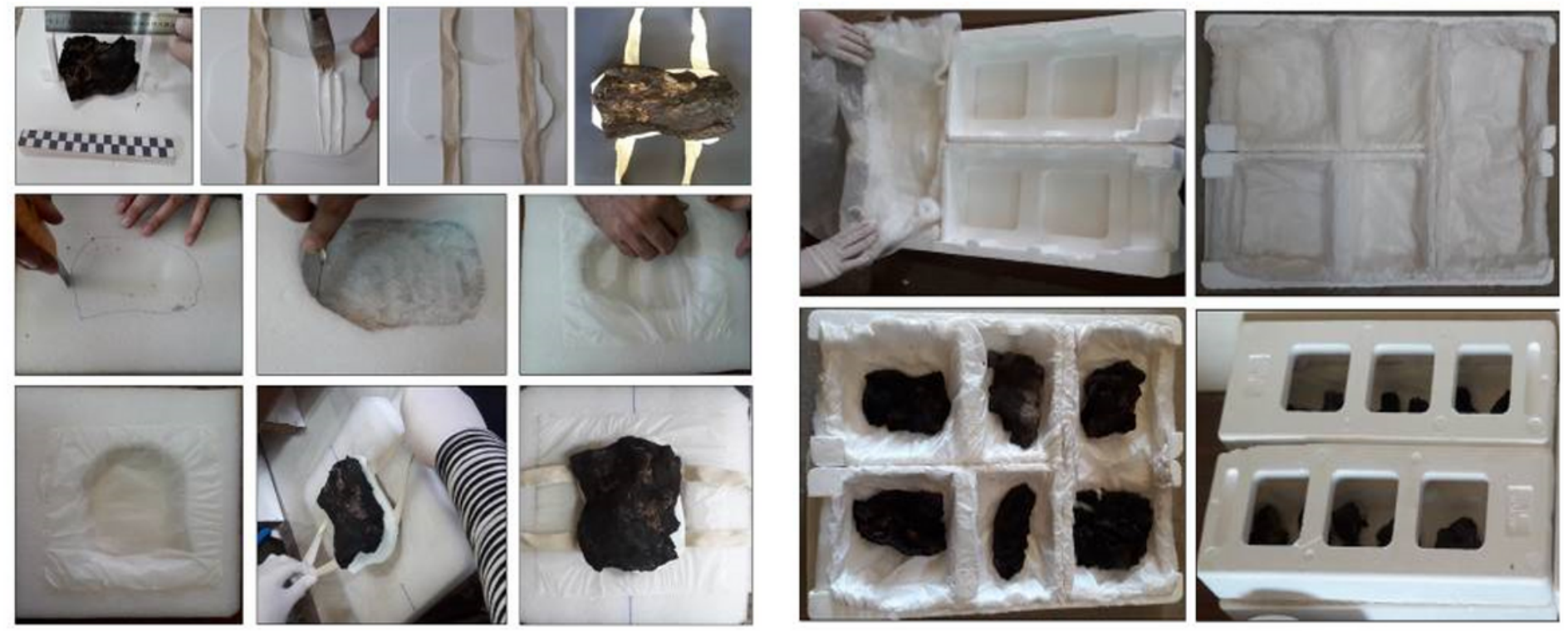

\section{Figure 8}

Preparation stages of carrier panels (left) and the process of packaging using lined drawers (right).
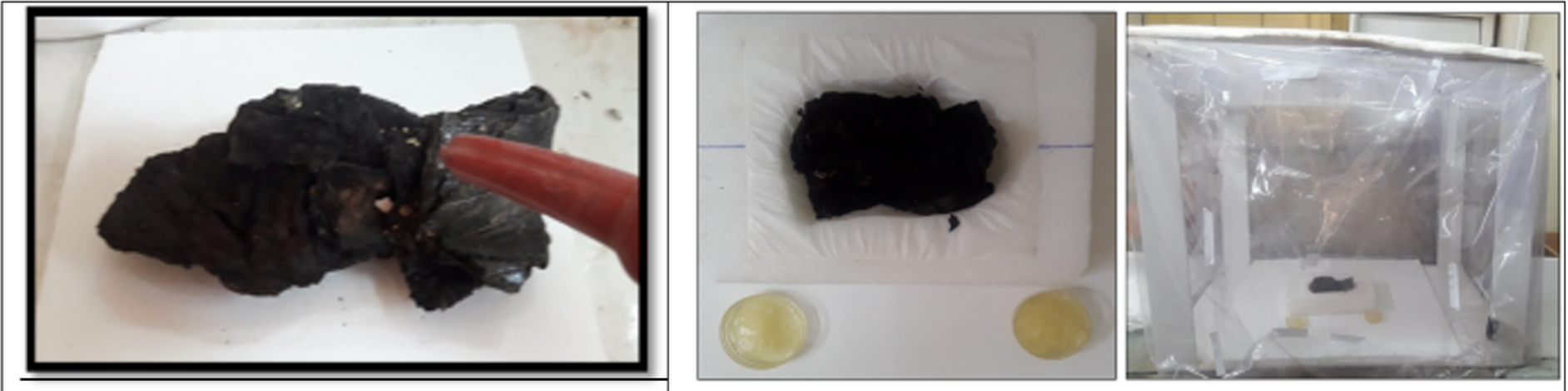

\section{Figure 9}

Mechanical cleaning process (left) and fumigation process using cedar oil inside polyethylene closed room (right). 

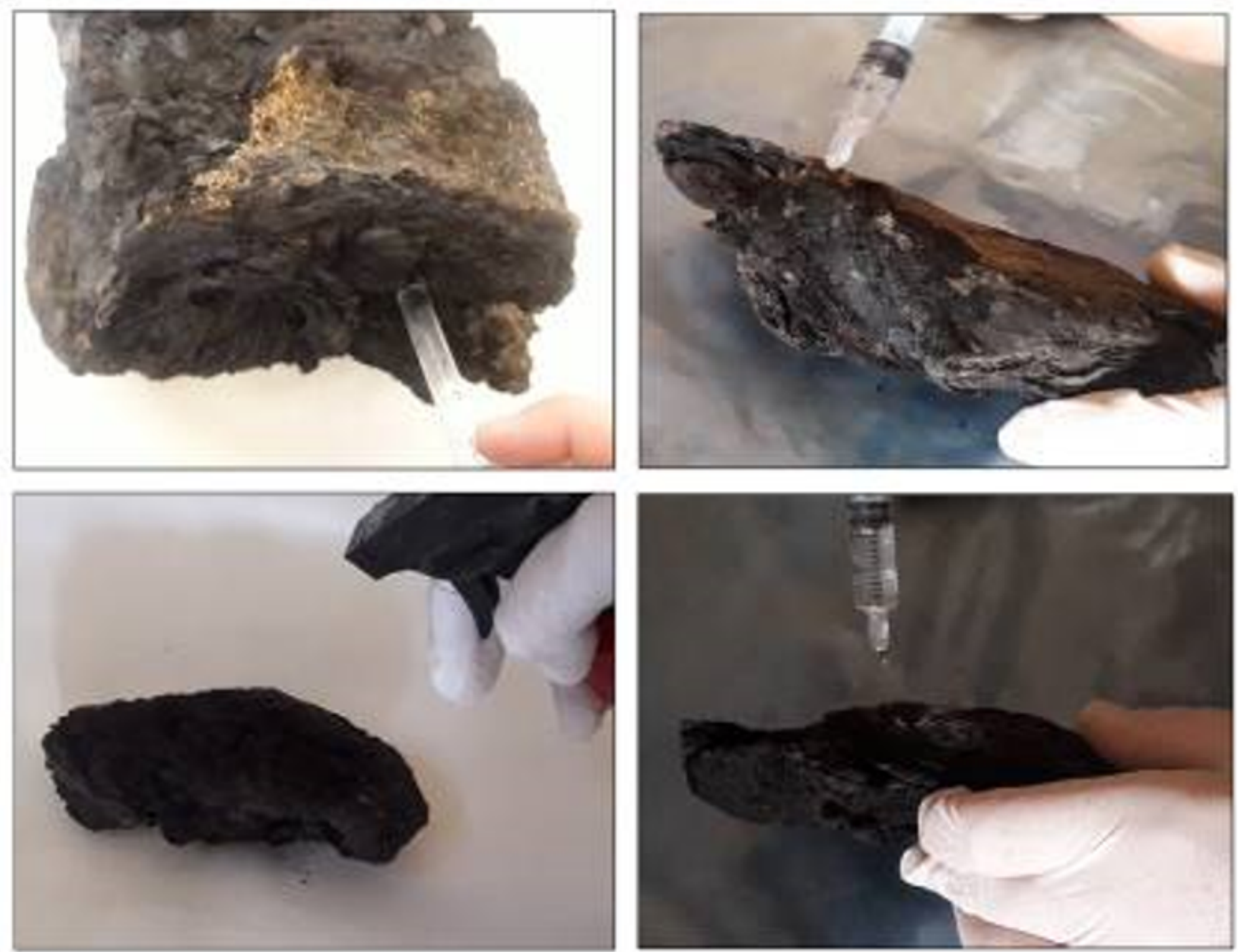

Figure 10

The Consolidation process by spraying and injecting technology. 

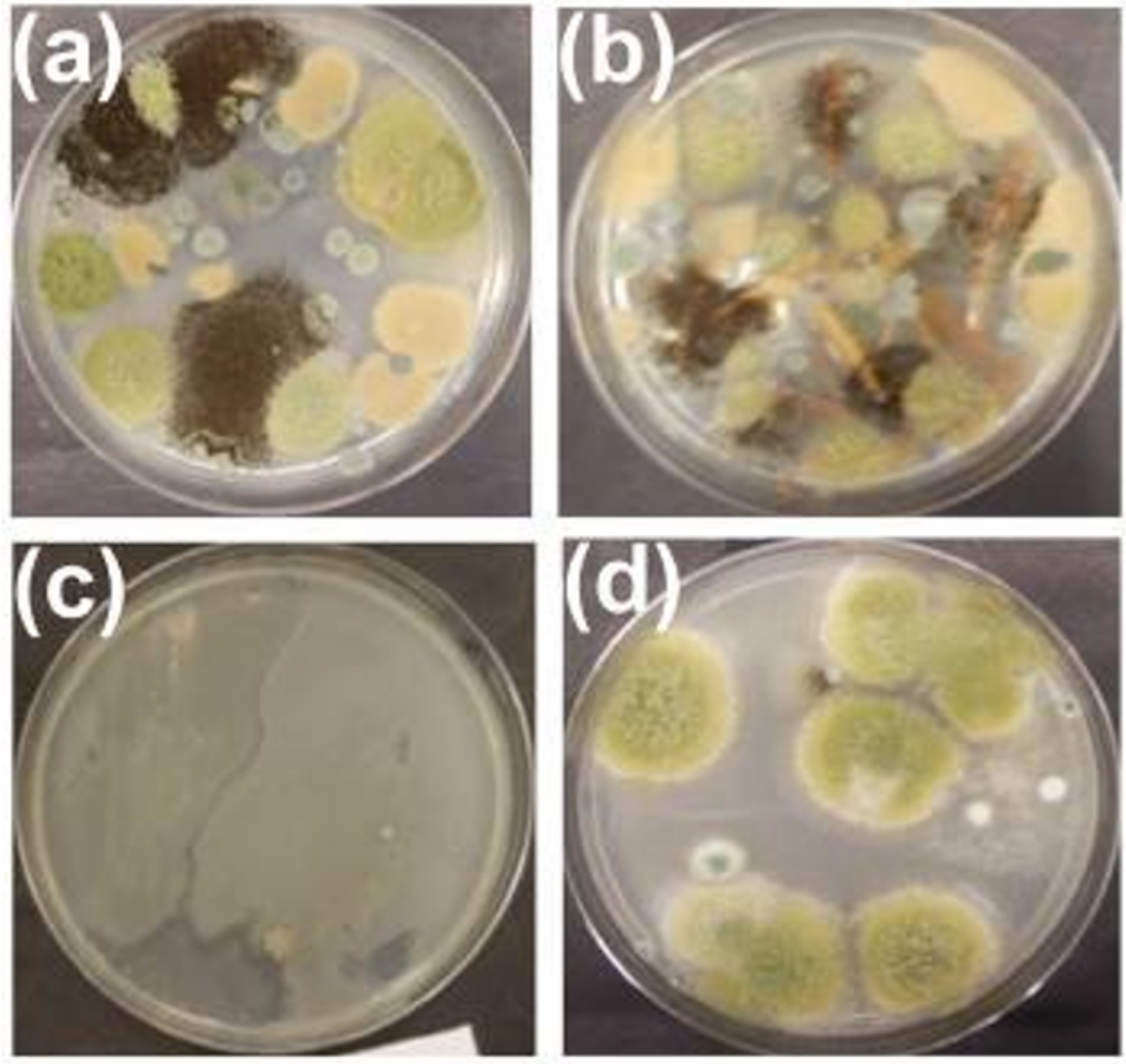

Figure 11

Microbial deterioration in different media including (a) PDA, (b) LCM, (c) nutrient agar, and (d) air sample. 

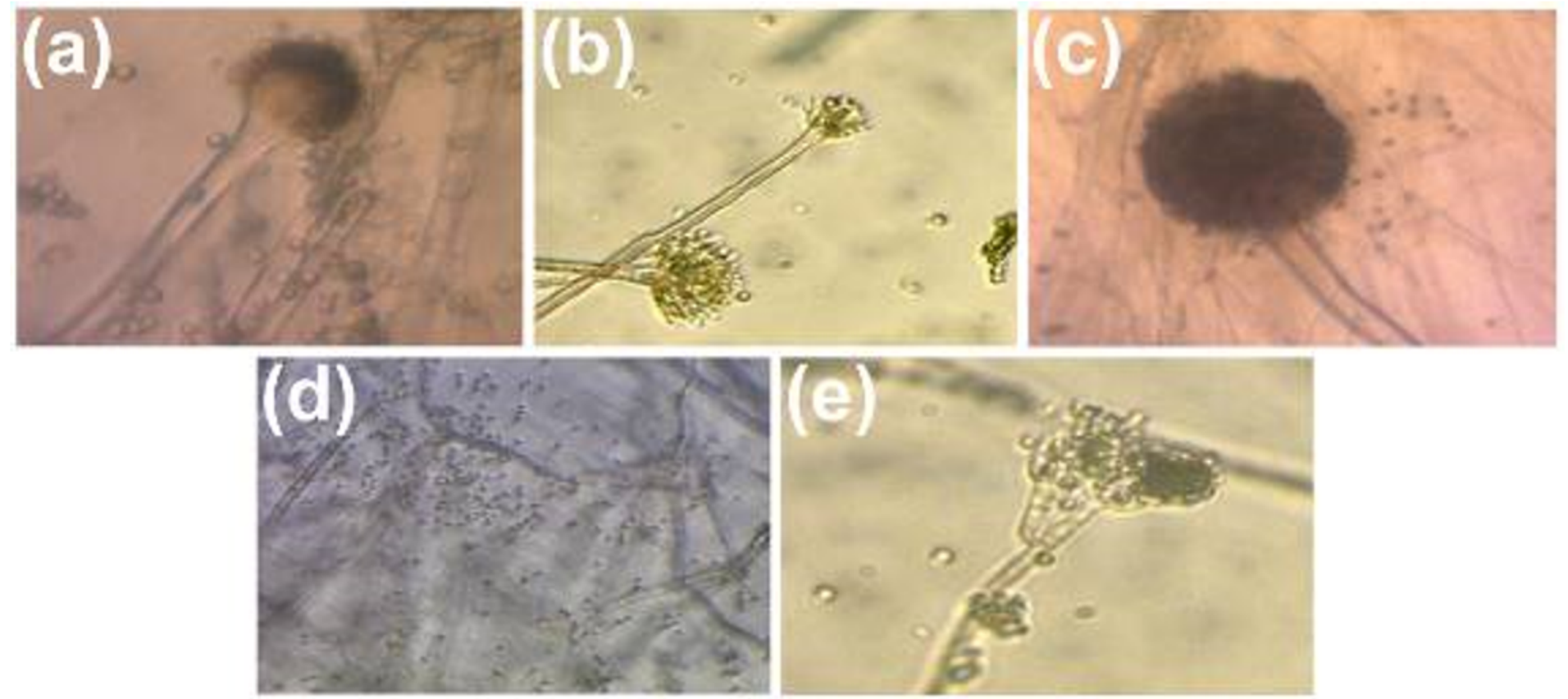

\section{Figure 12}

Microorganisms under light microscope; Aspergillus flavus (a), Aspergillus midulans (b), Aspergillus niger (c), Paecilomyces variotii (d), Penicillium sp. (e). 